\title{
Maternal and foetal outcome in women with neurological disorders
}

\section{Daphne Rose Thomas, Beenakumari R.*, Priya V.}

Department of Obstetrics and Gynecology, Govt. Medical College, Kottayam, Kerala, India

Received: 17 October 2019

Accepted: 15 November 2019

\section{*Correspondence:}

Dr. Beenakumari R.,

E-mail: drbeenakr@yahoo.co.in

Copyright: ( ) the author(s), publisher and licensee Medip Academy. This is an open-access article distributed under the terms of the Creative Commons Attribution Non-Commercial License, which permits unrestricted non-commercial use, distribution, and reproduction in any medium, provided the original work is properly cited.

\section{ABSTRACT}

Background: Wide spectrums of neurological disorders are observed in pregnancy and puerparium. These disorders can alter the course of pregnancy and pregnancy can worsen them.

Methods: This was a cross sectional observational study which included 154 patients in pregnancy and postpartum up to 6 weeks with neurological disorders admitted in department of obstetrics and gynecology, Government Medical College, Kottayam over a period of one year from December 2017. All patients underwent detailed general and systemic examination and were assessed by neurologist. After delivery maternal and foetal outcome and morbidity and mortality were observed.

Results: Out of total 5202 deliveries, 154 patients presented in pregnancy and puerparium with neurological disorders amounting to $2.96 \%$. The age of patients ranged from 18-44. The commonest neurological disorder was epilepsy $(60.4 \%)$. Other disorders were eclampsia $(7.8 \%)$, cerebrovascular disorders $(9.1 \%)$, brain tumors $(4.5 \%)$, cranial nerve palsy $(3.2 \%)$ and different types of other neurological disorders (14.9\%). The most common presentation was generalized tonic clonic seizures (82.8\%). $76.6 \%$ of patients had normal vaginal delivery and $13 \%$ underwent caesarean section. There were 5 cases of intrauterine death (3.2\%), 5 cases of foetal anomalies (3.2\%) and 3 cases of neonatal deaths $(1.9 \%)$. One case of maternal mortality was there due to intra-cerebral hemorhhage.

Conclusions: Epilepsy was the commonest disorder with good maternal and foetal outcome. Vascular disorders and eclampsia were associated with higher maternal and foetal morbidity and mortality.

Keywords: Eclampsia, Epilepsy, Pregnancy, Seizures

\section{INTRODUCTION}

Neurological disorders account for $20 \%$ of morbidity and mortality in pregnancy. ${ }^{1}$ A wide range of neurological conditions can affect women during pregnancy and puerparium. The primary neurological disorders in relation to pregnancy are epilepsy, eclampsia, cerebral venous thrombosis, migraine, Bell's palsy, stroke, central nervous system (CNS) tumours and demyelinating disorders. Secondary neurological disorders such as metabolic encephalopathies secondary to hypoxiaischemia, hypoglycaemia, hepatic failure, and azotemia also can present during pregnancy. ${ }^{2}$ Headache is another symptom during pregnancy which can be primary due to migraine or tension vascular headache. The causes of secondary headache include idiopathic intracranial hypertension, eclampsia, reversible cerebrovascular syndrome. ${ }^{3}$ Epilepsy is a diverse group of chronic neurological disorder characterised by recurrent unprovoked seizures. Neurological disorders like eclampsia and intracerebral haemorrhage $(\mathrm{ICH})$ may be prevented by timely management of hypertension in pregnancy. 4

Objectives of this study were to assess the profile of patients presenting with neurological disorders in 
pregnancy and puerparium. And to assess the maternal and foetal outcome in patients with neurological disorders.

\section{METHODS}

The cross sectional observational study conducted at department of obstetrics and gynecology, Government Medical College, Kottayam, Kerala, with 1 year from 1st December 2017.

Total 154 patients were included. All patients with neurological disorders in pregnancy and pueparium up to 6 weeks admitted in department of obstetrics and gynecology, Government Medical College, Kottayam, Kerala.

\section{Inclusion criteria}

- Patients with pre existing neurological disorder

- Patients developing primary neurological disorder during pregnancy and puerparium

- Patients with eclampsia.

\section{Exclusion criteria}

- All patients with neurological symptoms with associated psychiatric disorders

- All patients with headache who did not require neurological evaluation.

Institutional Review Board approval was obtained (IRB No:24/2017). Informed written consent was obtained from all patients. Using proforma a detailed history was taken. Central nervous system (CNS) examination was done in detail. Level of consciousness was assessed by Glasgow coma scale (GCS) followed by cranial nerve examination, motor and sensory system. All patients were evaluated by neurologist. Electro encephalo gram (EEG) and magnetic resonance imaging (MRI) of brain as advised by neurologist were done. Pregnancy was assessed by a team of senior consultants and appropriate decision for termination of pregnancy was taken. Maternal and foetal outcome was assessed. If advised by paediatrician neurosonogram of baby was taken. Patients were followed up to 6 weeks postpartum.

\section{Statistical analysis}

Data was entered in MS Excel and analysed using SPSS 24 software.

\section{RESULTS}

In this cross sectional study in department of obstetrics and gynecology, Govt. Medical College, Kottayam over a period of 1 year there was 5202 deliveries. Out of 5202 patients admitted in labour room 154 patients were identified to be having neurological disorders.
Table 1: Age group.

\begin{tabular}{|lll|}
\hline Age group & $\mathbf{N}$ & $\%$ \\
\hline$<20$ & 15 & 9.7 \\
\hline $21-30$ & 87 & 56.5 \\
\hline $31-40$ & 49 & 31.8 \\
\hline $41-50$ & 3 & 1.9 \\
\hline Total & $\mathbf{1 5 4}$ & $\mathbf{1 0 0}$ \\
\hline
\end{tabular}

Maximum number of patients were in the age group 2130 years.

Table 2: Presenting symptoms.

\begin{tabular}{|lll|}
\hline Symptoms & N & $\%$ \\
\hline GTCS & 95 & 61.7 \\
\hline CPS & 16 & 10.4 \\
\hline Hemiparesis and palsy & 15 & 9.7 \\
\hline Headache & 7 & 4.5 \\
\hline Lower limb weakness & 2 & 1.3 \\
\hline Chorea & 1 & 0.7 \\
\hline Ataxia & 2 & 1.3 \\
\hline Postpartum psychosis & 1 & 0.7 \\
\hline Asymptomatic & 15 & 9.7 \\
\hline Total & $\mathbf{1 5 4}$ & $\mathbf{1 0 0}$ \\
\hline
\end{tabular}

Majority of patients $(61.7 \%)$ presented with generalised tonic clonic seizures (GTCS). Next common symptom was complex partial seizures (CPS) $9.7 \%$ of patients were asymptomatic.

Table 3: Final diagnosis.

\begin{tabular}{|lll|}
\hline Diagnosis & $\mathbf{N}$ & $\%$ \\
\hline Cranial nerve palsy & 5 & 3.2 \\
\hline Eclampsia & 12 & 7.8 \\
\hline Epilepsy & 93 & 60.4 \\
\hline Others & 23 & 14.9 \\
\hline Tumors & 7 & 4.5 \\
\hline Vascular disorders & 14 & 9.1 \\
\hline Total & $\mathbf{1 5 4}$ & $\mathbf{1 0 0}$ \\
\hline
\end{tabular}

A total $60.4 \%$ of patients were diagnosed to have epilepsy which constituted the major proportion of neurological disorders. 14 patients had vascular disorders contributing $9.1 \%$.

Cerebral venous thrombosis (CVT) was the commonest vascular disorder followed by migraine. The diagnosis of CVT was confirmed by MRI. Sigmoid sinus and sagittal sinus thrombus were identified in CVT cases. Out of 14 patients 5 patients had associated gestational hypertension $(35.7 \%)$. Out of 2 patients with intracerebral haemorrhage $(\mathrm{ICH})$ one patient had midline shift and uncal herniation on MRI. Both were patients with severe pre-eclampsia and hypertensive crisis. 
Table 4: Different types of vascular disorders.

\begin{tabular}{|llll|}
\hline Vascular disorders & $\mathrm{N}$ & $\%$ & $\begin{array}{l}\% \text { of Total } \\
(\mathrm{N}=154)\end{array}$ \\
\hline $\begin{array}{l}\text { Cerebral venous thrombosis } \\
\text { (CVT) }\end{array}$ & 5 & 35.7 & 3.2 \\
\hline $\begin{array}{l}\text { Intra cerebral haemorhage } \\
(\mathrm{ICH})\end{array}$ & 2 & 14.3 & 1.3 \\
\hline Ischemic stroke & 2 & 14.3 & 1.3 \\
\hline Migraine & 3 & 21.4 & 1.9 \\
\hline $\begin{array}{l}\text { Posterior reversible } \\
\text { encephalopathy syndrome }\end{array}$ & 1 & 7.1 & 0.65 \\
\hline Sturge weber syndrome & 1 & 7.1 & 0.65 \\
\hline Total & $\mathbf{1 4}$ & $\mathbf{1 0 0}$ & $\mathbf{9 . 1}$ \\
\hline
\end{tabular}

Table 5: MRI findings in brain tumors.

\begin{tabular}{|lll|}
\hline MIRI findings & N & $\%$ \\
\hline Fibrous dysplasia & 1 & 14.3 \\
\hline Low grade astrocytoma & 1 & 14.3 \\
\hline Parasagital meningioma & 1 & 14.3 \\
\hline Retro cerebellar Arachnoids cyst & 1 & 14.3 \\
\hline $\begin{array}{l}\text { Tectal glioma and persistent cavum } \\
\text { septum pellucidum }\end{array}$ & 1 & 14.3 \\
\hline Nil (cutaneous neurofibroma) & 2 & 28.6 \\
\hline Total & $\mathbf{7}$ & $\mathbf{1 0 0}$ \\
\hline
\end{tabular}

Out of 7 patients with tumors, 2 had undergone surgery preconceptionally and were on anti-epileptic drugs (AED). One patient with tectal glioma had undergone ventriculo peritoneal shunt and one with retrocerebellar arachnoid cyst had undergone fenestration of cyst.

Cranial nerve palsy was found in 5 patients out of which 3 had Bells palsy, one with 3rd nerve palsy and one with bulbar paralysis. Out of these patients one had postviral encephalitis and one had myeloneuro radiculopathy on MRI. Other 3 had no findings in MRI.

Table 6: Other diagnosis.

\begin{tabular}{|lll|}
\hline Diagnosis & N & $\begin{array}{l}\% \text { of Total } \\
(\mathbf{N}=154)\end{array}$ \\
\hline Carpel tunnel syndrome & 2 & 0.65 \\
\hline Cerebral acqeduct stenosis & 1 & 0.65 \\
\hline Cerebral palsy & 1 & 0.65 \\
\hline Chiari malformation with syrinx & 1 & 0.65 \\
\hline Chorea & 1 & 0.65 \\
\hline Fascio scapulo humeral dystrophy & 1 & 0.65 \\
\hline Hashimotos encephalopathy & 1 & 0.65 \\
\hline Hippocampal sclerosis & 2 & 1.3 \\
\hline Multiple sclerosis & 1 & 0.65 \\
\hline Post-polio residual paralysis & 5 & 3.2 \\
\hline Primary dystonia & 2 & 1.3 \\
\hline Syringomelia & 1 & 0.65 \\
\hline Transverse myelitis with sequele & 1 & 0.65 \\
\hline Wernickes encephalopathy & 2 & 1.3 \\
\hline Temporal lobe mesial sclerosis & 1 & 0.65 \\
\hline Total & $\mathbf{2 3}$ & $\mathbf{1 4 . 9}$ \\
\hline
\end{tabular}

Table 7: Gestational age at which symptoms appeared.

\begin{tabular}{|lllllll|}
\hline Neurological disorder & $<28$ weeks & $28-34$ weeks & $34-37$ weeks & $>37$ weeks & Postpartum & Asymptomatic \\
\hline Epilepsy (N:93) & $10(10.7 \%)$ & $2(2.2 \%)$ & $5(5.3 \%)$ & $3(3.2 \%)$ & $2(2.2 \%)$ & $71(76.3 \%)$ \\
\hline Eclampsia (N:12) & 0 & $1(8.3 \%)$ & $6(50 \%)$ & $5(41.7 \%)$ & 0 & 0 \\
\hline Vascular disorders (N:14) & $1(7.2 \%)$ & $2(14.3 \%)$ & $1(7.1 \%)$ & $1(7.1 \%)$ & $3(21.4 \%)$ & $6(46.2 \%)$ \\
\hline Cranial nerve palsy (N:5) & $2(40 \%)$ & $2(40 \%)$ & 0 & 0 & 0 & $1(20 \%)$ \\
\hline Tumers (N:7) & 0 & 0 & 0 & 0 & $1(14.3 \%)$ & $6(85.7 \%)$ \\
\hline Others (N:23) & $7(30.4 \%)$ & 0 & 0 & 0 & $1(4.3 \%)$ & $15(65.2 \%)$ \\
\hline Total (N:154) (100\%) & $20(13.0 \%)$ & $7(4.5 \%)$ & $12(7.8 \%)$ & $9(5.8 \%)$ & $7(4.5 \%)$ & $99(64.3 \%)$ \\
\hline
\end{tabular}

Table 8: Pregnancy Outcome.

\begin{tabular}{|llllll|}
\hline Neurological disorders & FTND & FTCS & Preterm delivery & Preterm CS Instrumental delivery \\
\hline Epilepsy (N:93) & $78(83.9 \%)$ & $12(13.0 \%)$ & 0 & 0 & $3(3.2 \%)$ \\
\hline Eclampsia (N:12) & $1(8.3 \%)$ & $4(33.3 \%)$ & $5(41.7 \%)$ & $2(16.7 \%)$ & 0 \\
\hline Vascular disorders (N:14) & $10(71.4 \%)$ & 0 & $2(14.3 \%)$ & $2(14.3 \%)$ & 0 \\
\hline Tumors (N:7) & $6(85.7 \%)$ & $1(14.3 \%)$ & 0 & 0 & 0 \\
\hline Cranial nerve palsy (N:5) & $4(80 \%)$ & $1(20 \%)$ & 0 & 0 & 0 \\
\hline Others (N:23) & $19(82.6 \%)$ & $2(8.6 \%)$ & $1(4.3 \%)$ & 0 & $1(4.3 \%)$ \\
\hline Total (N:154) & $118(76.6 \%)$ & $20(13.0 \%)$ & $8(5.2 \%)$ & $4(2.6 \%)$ & $4(2.6 \%)$ \\
\hline
\end{tabular}

A total 5 patients had post-polio residual paralysis. Wernickes encephalopathy in 2 patients were secondary to hyperemesis gravidarum. One patient with temporal lobe mesial sclerosis underwent right anterior temporal 
lobectomy and amygdalohippocampectomy preconceptionally.

A total $64.3 \%$ of all patients with neurological disorders were asymptomatic during pregnancy and postpartum and majority of this group included patients with epilepsy. All patients with eclampsia manifested in the third trimester and majority after 37 weeks.

All patients with epilepsy, drugs were modified. All patients with eclampsia $\mathrm{MgSO}_{4}$ was given. All patients with CVT were put on anticoagulants. Patients with migraine were treated with analgesics.
Out of 154 patients, 118 patients $(76.62 \%)$ had undergone uncomplicated full-term normal delivery. 20 patients (12.98\%) had undergone full term caesarean section (CS). 2 patients with intracerebral haemorrhage underwent preterm CS.

None of epilepsy patients required intensive care unit (ICU) admission. Out of 5 eclampsia patients who needed ICU admission, one was ventilated due to recurrent convulsions. Out of 2 patients with $\mathrm{ICH}$ requiring ventilation, one patient expired on second postoperative day.

Table 9: Maternal morbidity and mortality.

\begin{tabular}{|llll|}
\hline Neurologial disorder & ICU admission & Ventilation & Mortality \\
\hline Eclampsia (N:12) & $5(41.7 \%)$ & $1(8.3 \%)$ & 0 \\
\hline Vascular disorders (N:14) & $5(35.7 \%)$ & $2(14.3 \%)$ & 1 \\
\hline Cranial nerve plasy (N:5) guillain barre syndrome & $1(20 \%)$ & $1(20 \%)$ & 0 \\
\hline Other neurological disorders N (23) & $2(8.7 \%)$ & 0 & 0 \\
\hline Total 154 & $\mathbf{1 3 ( 8 . 4 \% )}$ & $\mathbf{4 ( 2 . 5 \% )}$ & $\mathbf{1 ( 0 . 7 \% )}$ \\
\hline
\end{tabular}

Table 10: Foetal outcome.

\begin{tabular}{|lllllll|}
\hline Neurological disorders & Full term live birth & Preterm birth & IUD & RDS & ICU admission & NND \\
\hline Epilepsyn (N:93) & 94 (1Twin) & 0 & 0 & 5 & 7 & 1 \\
\hline Eclampsia (N:12) & 5 & 5 & 2 & 1 & 2 & 2 \\
\hline Vascular disorders (N): & 10 & 1 & 3 & 0 & 1 & 0 \\
\hline Tumors (N:7) & 7 & 0 & 0 & 0 & 0 & 0 \\
\hline Cranial nerve palsy (N:5) & 5 & 0 & 0 & 0 & 0 & 0 \\
\hline Others (N:23) & 22 & 1 & 0 & 0 & 0 & 0 \\
\hline Total neonates (N:155) & $144(92.9 \%)$ & $7(4.5 \%)$ & $5(3.2 \%)$ & $6(3.9 \%)$ & $10(6.5 \%)$ & $3(1.9 \%)$ \\
\hline
\end{tabular}

There were 5 foetal anomalies in epilepsy patients. The anomalies were congenital talipes equino varus, distal phalanges atrophy, hypoplastic left heart syndrome, hydronephrosis, lymphangioma tongue, and mesomelia. The drugs causing anomalies were carbamazepine, eptoin, leviteracetam, sodium valproate and clobazem. There were 3 neonatal deaths out of which 2 were preterm and one was due to hypoplastic left heart syndrome.

\section{DISCUSSION}

There were a wide variety of neurological disorders identified in our study. Out of 5202 deliveries during one year study period, 154 patients presented with neurological disorders amounting to a prevalence of $2.96 \%$. This is comparable to study conducted by Shubha et al $(1.21 \%)$, but higher than study conducted by Gupta et al $(0.58 \%)$ possibly due to better case detection. . $^{3,4}$

Majority of women were between 21-30 years of age and $64.3 \%$ of patients were asymptomatic during pregnancy.
Most common presentation was GTCS $(61.7 \%)$ followed by CPS $(10.4 \%)$ attributing to epilepsy being the commonest disorder $(60.4 \%)$. Similar observations are made in a study conducted by Sarella et al. ${ }^{5}$ The possible causes of seizures in pregnancy include epilepsy, eclampsia, intracerebral lesions like arteriovenous malformations and tumors, haemohrhagic or ischemic stroke, cerebral venous thrombosis and intracerebral haemorrhage. ${ }^{6}$ Infections, drug withdrawals, metabolic derangements like hypoglycaemia and hypocalcaemia can also cause convulsions. Diagnosis of idiopathic epilepsy is one of exclusion. ${ }^{7}$

In a recent study by Shubha et al timings of seizures showed a uniform pattern through all trimesters of pregnancy and postpartum. In our study majority of epilepsy patients had their last episode of convulsions pre conceptionally (76.3\%). The rest was distributed in all trimesters $(10.8 \%)$ and the least was in the postpartum period $(2.2 \%)$ From these findings we can infer that majority of patients were well counselled and disease was under control. Out of 93 patients with epilepsy 5 had 
foetal anomalies which were equally distributed among different groups of drugs. Commonly used AEDs are associated with 2 to 3 times increased risk of anomalies. Exposure to valproic acid has the greatest incidence. The teratogenic effects of lamotrigine and oxcarbamazepine are not significantly different from that of carbamazepine. In case of lamotrigine, a positive correlation between maternal dose and rates of major congenital anomalies has been identified. ${ }^{8}$

The incidence of vascular disorders in our study was $9.1 \%$ of neurological disorders which was comparable to the study by Gupta et al $(6.6 \%){ }^{4}$ There is an increased risk of thromboembolism leading to vascular disorders in pregnancy. This is mainly due to physiological changes in pregnancy like increase in blood volume with marked increase in red cell mass, increase in levels of factor VIII, IX, $\mathrm{X}$ and fibrinogen with an overall shift in procoagulant state. ${ }^{6}$ Hypercoagulability worsens after delivery due to dehydration, volume depletion and consumption of high fat food. ${ }^{9}$ Commonest symptom of CVT was headache followed by focal neurological deficits. Coma was the most consistent and strong predictor of a poor outcome. ${ }^{10}$ In our study out of 14 patients 5 had CVT. 3 of them presented in the postpartum period. Thromboses were seen in superior sagital and transverse sinus. All cases were treated with anticoagulants and had good maternal and foetal outcome.

Intra cerebral haemorrhage (ICH) constituted $1.2 \%$ of all neurological cases. All patients presented in third trimester with GTCS. Both patients had pre-eclampsia. Out of two patients one expired which was the only case of maternal mortality. Our findings were similar to study by Gupta et al. ${ }^{4}$ Pregnancy associated $\mathrm{ICH}$ is caused by severe pre-eclampsia, eclampsia or cerebrovascular malformation. $\mathrm{ICH}$ is reported to be the most common cause of maternal mortality in severe pre-eclampsia and eclampsia which contributes to $12 \%$ of all maternal deaths. ${ }^{11}$

Migraine was present in $1.9 \%$ of total cases. All had pre conceptional symptoms which improved during pregnancy. Migraine is considered to be a neurovascular disorder in which vasodialatation, serotonin release, and activation of $\mathrm{N}$ Methyl D Aspartate (NMDA) receptors and stimulation of central nervous system. It can present as classical migraine with head ache, nausea, vomiting, and photophobia with aura. It can also be associated with aphasia and hemianopia. ${ }^{6}$ Other common cause of head ache is tension vascular head ache which is moderate in intensity and bilateral. Causes of secondary head ache include infections, pre-eclampsia, ischemic or haemorrhagic stroke, cerebral venous thrombosis, subarachnoid haemorrhage and idiopathic intracranial hypertension. Red flags to secondary head ache are worst head ache experienced, acute onset or thunderclap head ache, hemicranial, worsens with decubitus or valsalva maneuver, associated with fever or focal neurological deficits and not relieved with symptomatic therapy. ${ }^{12}$
Eclampsia is new onset seizures in the setting of preeclampsia. Incidence of eclampsia was $7.8 \%$ which was much lower than the study by Shubha et al. ${ }^{3}$ This is due to the fact that majority of patients had adequate control of blood pressure. All cases occurred in third trimester, similar to the study by Saeed G et al. ${ }^{13}$ All patients were treated with magnesium sulphate with no further episode of convulsions. The adverse foetal outcome was $33.4 \%$ in the form of intrauterine death and neonatal death.

A total $3.2 \%$ of our patients had postpolio paralysis which was comparable to other studies. ${ }^{3}$ out of 5 were delivered by caesarean section and all had good maternal and foetal outcome.

There were three cases of encephalopathy in our study $(1.9 \%)$ of which two were Wernickes encephalopathy (WE) associated with hyperemesis gravidarum. WE develop due to acute thiamine deficiency characterized by the triad of nystagmus, altered mental status and ataxia. It is exacerbated by intravenous glucose administration. All patients with hyperemesis should be given $100 \mathrm{mg}$ of thiamine parenterally to prevent development of WE. ${ }^{6}$ MRI showed features of demyelination. The third case was of hashimotos encephalopathy. Other causes of encephalopathy include metabolic and hepatic encephalopathies which were not observed in our study.

Incidence of brain tumor was $4.5 \%$ comparable to other studies. Cranial nerve palsy was present in $3.2 \%$ of patients. Idiopathic facial palsy was common. Bells palsy is a lower motor neuron disease with unilateral weakness of fascial muscles, dry eyes, hyperacusis to acute sounds and loss of taste over the ipsilateral anterior two third of tongue. ${ }^{12}$ Prednisolone can be given to speed up recovery and $90 \%$ of cases resolve spontaneously. One case of Gullaine Barre syndrome presented at 31 weeks with bulbar paralysis. Intravenous immunoglobulin (IVIG) was given and patient recovered well.

There was one case of multiple sclerosis in our study Multiple sclerosis is an inflammatory demyelinating disease affecting CNS. Pregnancy has little or no deleterious effect. But risk of relapse in first three months postpartum was found to be $30 \% .^{6}$ Exclusive breast feeding has shown to have some beneficial effects on postpartum relapse rate. ${ }^{14}$

Two cases of carpel tunnel syndrome in our study presented with numbness and pain of index and middle fingers and adjacent surfaces of thumb and ring finger. Symptoms are precipitated by compression of median nerve in the carpel tunnel of wrist. Treatment includes analgesics and wrist splints. Most cases resolve spontaneously in the postpartum period. ${ }^{6}$

Many of other neurological conditions like Myesthenia Gravis, TB meningitis, pyogenic meningitis and viral encephalitis were not observed in our study probably because of short duration of study period. ${ }^{15}$ 


\section{CONCLUSION}

Epilepsy was the commonest disorder with good maternal and foetal outcome. Vascular disorders and eclampsia were associated with higher maternal and foetal morbidity and mortality.

\section{ACKNOWLEDGMENTS}

Authors would like to thank Dr Beena V, Professor of Neuromedicine Govt. Medical College, Kottayam, for her immense help and to Dr Siva P. M. for the statistical analysis.

\section{Funding: No funding sources}

Conflict of interest: None declared

Ethical approval: The study was approved by the Institutional Ethics Committee

\section{REFERENCES}

1. Tan SC, Jeng J. Management of stroke in pregnancy and puerparium. Expert Rev Neurother. 2010;10(2):205-15.

2. McDonald BK, Cockerell OC, Sander JW, Shorvon SD. The incidence and lifetime prevalence of neurological disorders in a prospective communitybased study in the UK. Brain. 2000;123(4):665-76.

3. Shubha L, Rao SV, Raghavendra S. Neurological disorders in pregnancy and puerparium. J Dent Med Sci. 2017;16(4)80-5.

4. Gupta S, Rohatgi A, Sharma. A study on neurological disorders during pregnancy and puerparium. Ann Indian Acad Neurol. 2006;9:157-7

5. Sarella LK, Rao DS. Neurological disorders in pregnancy and puerparium. Sri Lanka J Obstet Gynecol. 2014;36(3):117-22.

6. Kevat D, Mackillop L. Neurological diseases in pregnancy. J R Coll Physicians Edinb. 2013;43:4958.

7. Cunningham F, Leveno K, Bloom S, Spong CY, Dashe J. Neurological disorders. In Williams
Obstetrics, 24 ${ }^{\text {th }}$ Ed. Chapter 6, Mcgraw-hill; 2014:1189.

8. Perucca E. Birth defects after prenatal exposure to antiepileptic drugs. The Lancet Neurol. 2005;4(11):781-6.

9. Saroja AO, Tapsi C, Naik KR. Cerebral venous thrombosis in women from Indian subcontinent. J Sci Soc 2017;44:20-5.

10. Einhaupl K, Stam J, Bousser MG, De Bruijin SF, Ferro JM et al. EFNS guideline on the treatment of cerebral venous and sinus thrombosis in adult patient. Eu J Neurol. 2010;17(10):1229-35.

11. Liang ZW, Lin L, Gao WL, Feng LM. A clinical characteristic analysis of pregnancy-associated intracranial haemorrhage in China. Sci Rep. 2015;5, 9509.

12. Ferraz Z, Parra J, Ansa Luisa Areia, Elsa Vasco, Paulo Moura. Acute onset of Neurological disorders in Pregnancy: A Literature review. Rev Bras Ginecol Obstet 2017;69:560-8.

13. Saeed G, Wajid R, Dar AY. Maternal mortality in eclampsia after caesarean section versus vaginal delivery. Ann King Edward Med Univ. 2017;23(4):430-4.

14. Hellwig K, Haghikia A, Rockhoff M, Gold R. Multiple sclerosis and pregnancy experience from a nationwide database in Germany. Ther Adv Neurol Dis. 2012;5(5):247-53.

15. Madkar CS, Sinha G, Burute S, Puri MS, Salvi P. Neurological disorders in pregnancy and puerparium. still a significant cause of maternal morbidity and mortality in Rural India. Ind J Obstet Gynecol Res. 2018;5(1)118-23.

Cite this article as: Thomas DR, Beenakumari R, Priya V. Maternal and foetal outcome in women with neurological disorders. Int J Reprod Contracept Obstet Gynecol 2019;8:4891-6. 